ISSN (Print) : 1412-7601

ISSN (Online) : 2654-8712

Volume 6, No.2 September 2020

EKONOBIS

http://www.ekonobis.unram.ac.id

\title{
Kesiapan Masyarakat Desa Sekitar Kawasan Ekonomi Khusus (KEK) Untuk Berkontribusi Dalam Pengembangan Kawasan Ekonomi Khusus (KEK) Mandalika Kabupaten Lombok Tengah
}

\section{Gusti Lanang Ardana, Wahyunadi, Putu Karismawan, Abdul Manan, Musta'in} Universitas Mataram

\section{ARTICLE INFO}

Keywords : Mandalika Resort Development, Economic Development
Community Contribution,

ABSTRACT : The Mandalika Resort Special Economic Zone (KEK) is concentrated on economic development in the tourism sector, has been, will be and is being developed which is expected to accelerate economic development in Central Lombok Regency, West Nusa Tenggara Province, and to support the acceleration and expansion of Indonesia's economic development.

The development of the KEK MANDALIKA besides having an impact on the PDRB and PAD of Central Lombok must also be felt by the people around the KEK MANDALIKA. Therefore, the purpose of this study is to determine the readiness of the community to contribute to the development of the KEK MANDALIKA. The method used was a survey sample with primary data sources from 50 respondents in four selected villages by purposive sampling, namely, the villages of Kuta, Prabu, Mertak, and Sukadana. The results showed that $74 \%$ of residents were ready to contribute to various business fields, $24 \%$ were not ready for various reasons, and $2 \%$ said they were not ready. These business fields are general trading 32\%, general services 22\%, fisheries/fishermen 18\%, food stalls/restaurants $7 \%$, hotel labor services $7 \%$, and security $11 \%$, and agriculture $3 \%$.
Kata Kunci :

Kontribusi Masyarakat, Pengembangan Mandalika Resort, Pertumbuhan Ekonomi

ABSTRAK: Kawasan Ekonomi Khusus (KEK) Mandalika Resort terkonsentrasi pada pengembangan ekonomi di bidang pariwisata, telah, akan dan sedang dikembangkan yang diharapkan dapat mempercepat pembangunan perekonomian di Kabupaten Lombok Tengah, Provinsi Nusa Tenggara Barat, serta untuk menunjang percepatan dan perluasan pembangunan ekonomi Indonesia.

Pengembangan KEK MANDALIKA selain berdampak pada PDRB dan PAD Lombok Tengah harus dirasakan juga oleh masyarakat sekitar KEK MANDALIKA untuk itu tujuan dari penelitian ini adalah untuk mengetahui kesiapan masyarakat untuk berkontribusi dalam pengembangan KEK MANDALIKA. Metode yang digunakan adalah sampel survei dengan sumber data primer dari 50 responden di empat desa terpilih secara purposive sampling yaitu, Desa Kuta, Prabu, Mertak, dan Sukadana. Hasil penelitian menunjukan bahwa $74 \%$ warga siap berkontribusi pada berbagai bidang usaha, $24 \%$ belum siap dengan beragam alasan, dan $2 \%$ menyatakan tidak siap. Bidang-bidang usaha tersebut adalah perdagangan umum $32 \%$, jasa umum $22 \%$, perikanan/nelayan $18 \%$, warung/rumah makan $7 \%$, jasa tenaga kerja hotel $7 \%$, dan bidang keamanan $11 \%$, dan bidang pertanian $3 \%$.

Corresponding Author:

Alamat : Program Studi Ekonomi Pembangunan, Fakultas Ekonomi dan Bisnis, Universitas Mataram, Jln. Majapahit No. 62 Mataram.

e-mail: 


\section{PENDAHULUAN}

\section{Latar Belakang}

Provinsi Nusa Tenggara Barat merupakan salah satu provinsi tujuan wisata di Indonesia. Maka pemerintah Provinsi Nusa Tenggara Barat terus berupaya untuk mengembangkan kepariwisataannya. Pengembangan kepariwisataan tersebut tentu didasarkan pada potensi kepariwisataan yang dimiliki seperti: wisata pantai, budaya, kerajinan, wisata alam dan lainnya. Salah satu bentuk perhatian pemerintah baik pusat maupun daerah dalam rangka pengembangan pariwisata di Nusa Tenggara Barat, semenjak dikeluarkannya Peraturan Pemerintah Nomor 52 Tahun 2014 tentang Kawasan Ekonomi Khusus (KEK) Mandalika Resort, Nusa Tenggara Barat ditetapkan sebagai salah satu wilayah pengembangan Kawasan Ekonomi Khusus di Indonesia disamping pengembangan ekonomi khusus lainnya yaitu: KEK Morotai di Provinsi Maluku Utara dan KEK Tanjung Api-Api di Sumatera Selatan.

Kawasan Ekonomi Khusus (KEK) Mandalika Resort terkonsentrasi pada pengembangan ekonomi di bidang pariwisata, telah, akan dan sedang dikembangkan yang diharapkan dapat mempercepat pembangunan perekonomian di Kabupaten Lombok Tengah, Provinsi Nusa Tenggara Barat, serta untuk menunjang percepatan dan perluasan pembangunan ekonomi Indonesia.

Kabupaten Lombok Tengah sebagai pusat pengembangan KEK Nusa Tenggara Barat dicanangkan pemerintah sebagai salah satu primadona koridor V. Fasilitas pariwisata yang akan dibangun dan dikembangkan antara lain adalah high end and low density hotel, villas, apartments, resorts, residential. Dilengkapi juga dengan 18 holes golf course, fasilitas leisure/recreation, medical/wellness center, training centre, art village, marina dan lain sebagainya. Pembangunan dan pengembangan KEK Mandalika juga akan menerapkan konsep eco green dan event based destination. Dengan konsep eco green, fasilitas pariwisata yang akan dibangun harus berstandar eco green sehingga akan meningkatkan nilai jual kawasan. Sedangkan konsep event based destination akan menonjolkan penyediaan fasilitas pariwisata non akomodasi bertaraf internasional yang akan menjadi daya tarik wisatawan sambil menikmati keindahan kawasan pariwisata Mandalika Lombok (Lomboknews.com, Mei 2015). 
Upaya pengelolaan obyek-obyek daerah tujuan wisata di Kabupaten Lombok Tengah menunjukkan perkembangan yang cukup menggembirakan, hal ini ditunjukkan dengan meningkatnya jumlah wisatawan yang berkunjung. Jumlah kunjungan ke obyek wisata di Kabupaten Lombok Tengah selama tahun 2016 sebanyak 614.906 orang, terdiri dari 480.154 wisatawan asing dan 134.752 wisatawan domestik. Bila dilihat lima tahun terakhir, tahun 2014 merupakan tahun terbanyak orang berkunjung ke obyek wisata. Minat wisatawan asing lebih besar untuk berkunjung ke obyek wisata dibandingkan wisatawan domestik. Selama tahun 2016, sekitar 78\% wisatawan asing yang berkunjung ke obyek wisata (Lombok Tengah dalam Angka, 2017). Di samping itu ditunjang dengan fasilitas dan akomodasi yang memadai. Kabupaten Lombok Tengah telah memiliki fasilitas hotel baik bintang maupun melati serta akomodasi lainnya (losmen, bungalow, dan lain-lain). Pada tahun 2016, jumlah hotel/bungalow yang tersedia di Kabupaten Lombok Tengah tercatat sebanyak 50 buah dengan 675 kamar dan 765 tempat tidur.

Pengembangan pariwisata di Kabupaten Lombok Tengah sebagai sektor unggulan diharapkan dapat menggerakkan industri- industri kecil meraih peluang keuntungan dari sektor pariwisata dalam meningkatkan penerimaan daerah di sektor pariwisata.

Dalam laporan hasil penelitian tentang "Pengaruh Pengembangan Kawasan Ekonomi Khusus (KEK) Mandalika Resort terhadap Penerimaan Daerah dari Sektor Pariwisata di Kabupaten Lombok Tengah" oleh Drs. I Gusti Lanang Ardana, MS dkk Tahun 2018, disimpulkan beberapa hal antara lain:

1) KEK Mandalika menambah luasan kawasan sesuai dengan kebutuhan perencanaan dengan profil pembangunan: Iuas kawasan 1.175 ha, dengan pengelolaannya adalah PT. ITDC (International Tourism Development Coorporation) dengan kegiatan utama di bidang pariwisata.

2) Perkiraan nilai investasi pembangunan KEK Mandalika sekitar Rp2,2 triliundan perkiraan dapat menarik investasi swasta sebesar Rp28,63 triliun sampai dengan tahun 2025.

3) Dari sisi manfaat untuk daerah, ternyata manfaat yang dapat diperoleh untuk daerah Lombok Tengah adalah: dengan adanya KEK Mandalika dapat meningkatkan Pendapatan Asli Daerah (PAD) dari peningkatan jumlah kunjungan 
wisatawan dari tahun ke tahun selama periode 2013-2017. Rata-rata peningkatan PAD adalah 10,7\% pertahun, lonjakan kunjungan wisatawan ke Lombok Tengah sebesar 84\% pada tahun 2017, yaitu dari 108.917 orang tahun 2016 menjadi 200.483 orang tahun 2017.

Selanjutnya direkomendasikan untuk dapat menarik manfaat lebih besar bagi masyarakat dari sisi ekonomi dan lainnya, kiranya perlu untuk memberdayakan masyarakat sekitar kawasan, agar berkemampuan menangkap peluang dari keberadaan KEK Mandalika, yang bisa diawali dengan penelitian lebih lanjut tentang kesiapan masyarakat sekitar kawasan pengembangan KEK Mandalika tersebut. Oleh karena itu maka penelitian dengan judul “Kesiapan Masyarakat Desa Sekitar Kawasan Ekonomi Khusus (KEK) untuk Berkontribusi dalam Pengembangan Kawasan Ekonomi Khusus (KEK) Mandalika Kabupaten Lombok Tengah” perlu dilaksanakan.

\section{KAJIAN PUSTAKA}

\section{Potensi Wisata}

Lombok Tengah merupakan wilayah yang memiliki potensi wisata yang tidak kalah dengan daerah-daerah yang terdapat di Indonesia. Lombok Tengah juga merupakan gerbang masuk wisatawan yang menggunakan jasa transportasi udara yang berkunjung ke daerah ini karena adanya Bandara Internasional Lombok (BIL). BIL menjadi salah satu sarana yang menunjang perkembangan obyek wisata Lombok Tengah secara umum. Tempat-tempat yang memiliki potensi wisata di Lombok Tengah antara lain sebagai berikut:

1. Obyek Wisata Alam (Hutan atau Perairan Pedalaman)

a. Benang Setokel dan Benang Kelambu. Daya tariknya adalah air terjun, outbondarea, camping, keindahan alam serta pengamatan flora dan fauna. Jarak dari Kota Praya sekitar $30 \mathrm{~km}$

b. Aik Bukak. Daya tariknya adalah pemandian kolam renang, Outbond Area Camping, dan keindahan alam yang masih alami. Jarak dari Kota Praya sekitar 30 km

2. Obyek Wisata Alam (Bahari)

a. Pantai Gerepuk dan Pantai Awang daya tariknya adalah keindahan pantai dengan pasir putihnya, perkampungan nelayan, budidaya rumput laut serta mempunyai ombak yang bagus untuk surving.

b. Pantai Tanjung Aan daya tariknya adalah keindahan pantai yang 
masih alami, cuaca yang panas sangat bagus untuk tempat berjemur, dan ombaknya yang tenang serta keindahan bawah lautnya.

c. Pantai Kuta dan Pantai Seger daya tarik pantai ini adalah pesona keindahan pantai dan keindahan bawah lautnya masih sangat alami, perbukitan, dan kedua pantai ini juga sebagai tempat diadakannya festival Bau Nyale.

d. Selong Belanak daya tarik utama pantai ini adalah garis pantai yang luas, hamparan pasir putih yang masih alami, kampung nelayan, perbukitan yang hijau serta ombaknya yang tenang sehingga sangat cocok untuk olahraga senorkling.

e. Pantai Mawi daya tariknya adalah surganya bagi pencinta olahraga surving atau selancar karena pantai ini memiliki ombak terbaik dibandingkan pantai-pantai lainnya serta keindahan pantai ini yang diapit oleh perbukitan sehingga sangat cocok untuk tempat bersantai.

f. Pantai Are Guling daya tarik utama pantai ini adalah tempat berkumpulnya para pencinta olahraga terjun payung karena pesona keindahan kawasan pantai ini sangat mendukung untuk hobi yang satu ini.

g. Pantai Mawun daya tarik dari pantai ini adalah pasir putih, perbukitan, sunset, dan keindahan bawah laut. Pesona pantai ini sangat cocok untuk para wisatawan yang ingin menghabiskan waktunya untuk bersantai

3. Obyek Wisata Alam (Geologi dan Vulkanologi)

a. Gunung Rinjani, daya tarik yang disuguhkan ditempat ini adalah kegiata trekking, pengamatan flora dan fauna, photografi, mancing di danau dan dapat juga dipakai untuk wisata religi.

4. Obyek Wisata Budaya (Peninggalan Sejarah)

a. Dusun Sade dan Dusun Nde, adalah rumah tradisional, kampung tradisional, tipologi permukiman suku sasak, kesenian daerah dan upacara adat

b. Masjid Kuno, Rembitan, Masjid Gunung Pujut adalah masjid kuno, tipologi permukiman Suku Sasak dan upacara agama 
c. Makam Nyatok adalah makam Tokoh Agama Islam dan Makam Raja Pejanggik. Aktivitas wisata yang bisa dilakukan adalah belajar menenun, photografi, wisata ziarah, pengamatan upacara agama dan penelitian.

5. Obyek Wisata Budaya (Kehidupan Masyarakat)

a. Kerajinan Gerabah Penujak, Kerajinan Tenun Tradisional Sukarare, dan Kerajinan Anyaman Rotan/ Ketak Beleke. Aktivitas wisata adalah study tour, penelitian dan shopping. Pesona dari ketiga wisata ini adalah kerajinan asli Suku Sasak.

6. Obyek Wisata Buatan (Olahraga Khusus)

a. Bendungan Pengga dan Bendungan Batujai. Daya tarik utama wisata ini adalah keindahan bendungan dengan bangunan yang masih terjaga sangat kokoh serta keindahan alam disekitar bendungan yang masih alami.

7. Obyek Wisata Buatan (Festival Khusus)

a. Peresean daya tariknya adalah tarung peresean yang merupakan kesenian khas Suku Sasak Lombok yang dulunya bermula sebagai sebuah simbolis kegembiraan atau luapan emosi para prajurit Lombok dulu kala setelah berhasil melumpuhkan atau mengalahkan lawan di medan tempur.

b. Bau Nyale daya tariknya adalah kepercayaan masyarakat Lombok yang masih melekat tentang legenda Putri Mandalika serta keindahan alamnya yang masih terjaga secara alami.

c. Gendang Belek daya tariknya adalah alat musik kesenian Suku Sasak Lombok yang sering dimainkan pada saat upacara adat.

\section{METODE PENELITIAN}

\section{Metode Penelitian}

Penelitian menggunakan metode deskriptif eksploratif dengan pra survey dan sampel survey. Data pokok yang dikumpulkan adalah data primer dan data sekunder, meliputi data potensi desa-desa sekitar Kawasan Ekonomi Khusus Mandalika. Dari 16 desa di Kecamatan Pujut dipilih 4 desa terdekat dengan pusat pengembangan KEK Mandalika secara purposive sampling. Data sekunder meliputi data potensi sumber daya alam, sumber daya manusia, perdagangan, jasa tenaga kerja dan potensi sosial budaya. Sedangkan data primernya meliputi data 
|108 I Gusti Lanang Ardana, Wahyunadi, Putu Karismawan, A6dul Manan, Musta’in/Kesiapan Masyarakat...

kesiapan masyarakat untuk berkontribusi dalam pengembangan KEK Mandalika.

\section{Metode Pengumpulan Data}

Metode pengumpulan data adalah sampel survei, dikombinasikan dengan studi kepustakaan dan observasi.

\section{Penentuan Sampel Responden}

Dari 4 desa terpilih secara purposive sampling, dipilih 50 responden, dengan komposisi sebagai berikut:

1. Desa Kuta 17 orang;

2. Desa Prabu 12 orang;

3. Desa Mertak 12 orang;

4. Desa Sukadana 9 orang.

Selain data primer dari para responden juga akan dikumpulkan data sekunder dari sumber-sumber: Badan Pusat Statistik, instansi terkait dan dari penelusuran kepustakaan, berupa data potensi alam, kependudukan (tenaga kerja), potensi sosial budaya dan potensi jasa-jasa tenaga kerja.

\section{Jenis dan Sumber Data}

1. Jenis Data. Data yang dikumpulkan mencakup:

a. Data potensi sumber daya alam, utamanya sumber daya pertanian, peternakan dan perikanan.

b. Data potensi sumber daya manusia/ketenagakerjaan, utamanya data pendidikan, jenis pekerjaan dan usia. c. Data potensi sosial budaya, utamanya adat istiadat dan kesenian daerah.

d. Data potensi industri kerajinan/rumah tangga, jasa-jasa dan usaha perdagangan.

2. Sumber Data

a. Data primer diperoleh dari responden.

b. Data sekunder diperoleh dari berbagai instansi terkecil, utamanya BPS, BAPPEDA dan Dinas Pariwisata.

\section{Analisa}

Alat analisa data yang digunakan adalah analisa tabel silang, distribusi frekuensi dan disperse atau proporsi relatif. Analisis ini bersifat kualitatif.

\section{HASIL DAN PEMBAHASAN}

Sejak tahun 2008, ITDC ditugaskan oleh pemerintah Republik Indonesia untuk mengelola lahan seluas $1.175 \mathrm{Ha}$ di Kawasan Pariwisata Mandalika (Mandalika Resort), Kecamatan Pujut, Kabupaten Lombok Tengah, Provinsi NTB untuk dikembangkan menjadi Kawasan Pariwisata Terpadu. Untuk mendukung dan mempercepat rencana pengembangan Mandalika Resort, ITDC melaksanakan beberapa program akselerasi yang diharapkan dapat 
memberikan dampak secara langsung untuk terwujudnya pembangunan dan pengembangan Mandalika Resort.

PT Pengembangan Pariwisata Indonesia (Persero) pada tahun 2012 merencanakan kegiatan pembangunan dengan mengacu pada Master Plan Pengembangan Kawasan Pariwisata Mandalika. Deskripsi kegiatan yang akan dilakukan adalah membangun kamar sebanyak 10.335 buah, 1.585 unit residensial, dan fasilitas penunjang jalan sepanjang $10 \mathrm{~km}$, jaringan air kotor 26 km, IPAL kapasitas $320 \mathrm{~m}^{3} /$ hari, kapasitas listrik $123 \mathrm{MVA}$, dan lainnya) pada lahan seluas 1250 ha. Kegiatan pengembangan tersebut telah mendapatkan Surat Keputusan Kelayakan Lingkungan Hidup (SKKLH) No.660 Tahun 2012 yang selanjutnya mendapatkan ljin Lingkungan berdasarkan Keputusan Gubernur NTB Nomor 48 Tahun 2013.

Pada tahun 2018, berdasarkan perkembangan dan perubahan pasar pariwisata dunia, PT Pengembangan Pariwisata Indonesia (Persero) berencana melakukan perubahan pengembangan Kawasan Pariwisata Mandalika agar sesuai dengan Master Plan yang baru. Deskripsi perubahan meliputi penambahan jumlah kamar menjadi 26.737 buah, 5.384 unit residential dan fasilitas penunjang jalan sepanjang $50 \mathrm{~km}$, jaringan air kotor $34 \mathrm{~km}$,
IPAL kapasitas $1.800 \mathrm{~m}^{3} /$ hari, kapasitas listrik 260 MVA dengan penambahan Pembangkit Listrik Tenaga Surya, Sumber Air dengan Sea Water Reverse Osmosis, Monorail Kawasan, dan lainnya). Adanya perubahan rencana kegiatan dan/atau usaha yang dilakukan oleh ITDC ini memerlukan harmonisasi perizinan yang sudah dimiliki.

Alasan-alasan ketidaksiapan/belum siap mereka itu beragam: antara lain adanya persoalan pembahasan lahan yang belum selesai antara pemerintah/ITDC dengan warga, terutama warga Desa Kuta, kepemilikan modal, kapasitas, pengalaman dan lain-lain. Di samping itu, sosialisasi tentang program KEK Mandalika yang kurang dari ITDC dan dari pihak-pihak terkait. Sebagian besar warga juga belum pernah mengikuti pelatihanpelatihan terkait bidang pengembangan kepariwisataan. Di antara warga yang menyatakan siap, mensyaratkan adanya ketersediaan bantuan modal dari pihak lain dan harus dibekali dengan kemampuan-kemampuan untuk peningkatan pengetahuan dan keterampilan terkait kepariwisataan. Adapun kesiapan di bidang usaha untuk berkontribusi sebagai berikut: 
|110 I Gusti Lanang Ardana, Wahyunadi, Putu Karismawan, A6dul Manan, Musta'in/Kesiapan Masyarakat...

Tabel 1. Kesiapan masyarakat menurut bidang usaha

\begin{tabular}{|l|l|l|}
\hline No. & \multicolumn{1}{|c|}{ Bidang Usaha } & \multicolumn{1}{|c|}{ Persentase (\%) } \\
\hline 1 & Bidang perdagangan umum & 32 \\
\hline 2 & Bidang jasa umum & 22 \\
\hline 3 & Bidang perikanan/nelayan & 18 \\
\hline 4 & Warung/rumah makan & 7 \\
\hline 5 & Perhotelan/jasa tenaka kerja & 7 \\
\hline 6 & Bidang keamanan/satpam & 11 \\
\hline 7 & Bidang pertanian & 3 \\
\hline & Total & 100 \\
\hline
\end{tabular}

Selanjutnya, perlu dijelaskan tentang dengan kesiapan berkontribusi. Hal ini Hubungan Tingkat Pendidikan Responden dapat ditunjukan pada tabel berikut :

Tabel 2. Kesiapan berkontribusi menurut tingkat pendidikan

\begin{tabular}{|l|l|l|l|l|}
\hline \multicolumn{1}{|c|}{ Pendidikan } & \multicolumn{1}{|c|}{ Siap } & Belum siap & \multicolumn{1}{c|}{ Tidak siap } & Jumlah \\
\hline Sarjana & 1 & - & - & 1 \\
\hline SMA & 15 & 3 & - & 18 \\
\hline SMP & 4 & 1 & - & 5 \\
\hline SD & 8 & - & - & 8 \\
\hline TT.SD & 5 & 1 & 1 & 7 \\
\hline & 32 & 4 & 1 & 39 \\
\hline & $85 \%$ & $13 \%$ & $2 \%$ & $100 \%$ \\
\hline
\end{tabular}

Ternyata kesiapan waragan dikawasan KEK MANDALIKA tidak berkaitan dengan tingkat pendidikan. Hal ini di tunjukan oleh mayoritas warga menyatakan diap berkontribusi sebanyak $85 \%$, baik yang berpendidikan Sarjana sampai yang tdak tamat SD, Sisanya sebanyak $15 \%$ menyatakan BELUM SIAP dan TIDAK SIAP. Dari kenyataan ini yang menentukan kesiapan dalam berkontribusi adalah lebih banyak terkait dengan persoalanpersoalan yang menyangkut pembebasan lahan oleh ITDC dan kesediaan modal, kapasitas, pengalaman dan lain-lain. 
Selanjutnya, dilihat dari tingkat dalam golongan pendapatan yang rendah pendapatan responden warga kawasan hal ini dapat ditampilkan pada tabel KEK Mandalika sebagian besar masih berikut :

Tabel 3. Tingkat pendapatan responden warga kawasan kek mandalika

\begin{tabular}{|l|l|l|}
\hline \multicolumn{1}{|c|}{ Golongan pedapatan } & \multicolumn{1}{c|}{ FREKUENSI } & \multicolumn{1}{c|}{ Persen } \\
\hline$<1000.000$ & 7 & 14 \\
\hline $1000.000-1.500 .000$ & 32 & 64 \\
\hline$>2000.000$ & 11 & 50 \\
\hline Jumlah & 50 & 100 \\
\hline
\end{tabular}

Sumber: Data Primer.

Pendapatan warga kawasan KEK

KESIMPULAN DAN SARAN

MANDALIKA masih tergolong rendah (miskin). Sebagian besar (55\%) berpenghasilan antara 1000.000 1.500.000., per bulan. Bahka terdapat $13 \%$ (4 orang yang berpenghasilan $<1000.000 /$ bulan). Dengan kondisi seperti ini sudah tentu mereka sangat berharap dapat meningkatkan taraf hidup/pendapatan dari keberadaan pengembangan periwisata KEK MANDALIKA.

Dari fakta-fakta terkait kondisi warga/responden di 4 desa kawasan KEK Mandalika, yang telah menyatakan kesiapannya untuk berkontribusi (74\%), tampaknya diperlukan dukungan dan bantuan dari pemerintah dan pengelola KEK Madalika (PT. ITDC) agar mereka mampu merealisasikan kesiapannya tersebut.

\section{Kesimpulan}

Dari hasil Penelitan dan pembahasan, dapat disimpulkan hasil-hasil sebagai berikut:

1. Dengan pengembangan KEK Mandalika di kecamatan pujut, Kabupaten Lombok Tengah, dimaksudkan agar dapat memberikan manfaat dala segi (indikator) yaitu peningkatan PDRB Kabupaten Lombok Tengah dan juga peningkatan Pendapatan Asli Daerah (PAD), disamping itu juga agar dapat meningkatkan Negara dari Non Migas. Sedangkan manfaat bagi Masyarakat sekitar kawasan adalah untuk mendapat lapangan usaha baru, di tingkat Desa, Kecamatan dan Kabupaten, yang berujung kepada peningkatan kesejahteraan masyarakat. 
2. Dari data Primer yang dikumpulkan dari 50 responden di 4 desa terpilih, sebagian besar (74\%) mengatakan siap untuk berkontribusi dalam pengembangan KEK Mandalika. Sedangkan yang mengatakan belum siap adalah sebanyak (24\%) dan sisanya mengatakan tidak siap (2\%).

3. Mereka yang mengatakan siap berkotribusi sebanyak $74 \%$ tersebut berharap merealisasikan kesiapan dimaksud, Pemerintah dan atau pihak terkait lainnya dapat membantu memberdayakan mereke, seperti di bidang permodalan, pelatihan keterampilan dan lainnya terkait kepariwisataan.

4. Bidang-bidang usaha yang mereka menyatakan kesiapan adalah di bidang perdagangan umum (32\%), jasa umum (22\%), perikana/nelayan(18\%), keamana/satpam (11\%). Sedangkan di bidang pertanian hanya (3\%), Hal ini mengonfirmasi bahwa bidang petanian kurang diminati.

5. Fakta-fakta penting yang ditemukan terkait dengan kondisi dari 50 responden tersebut adalah dari segi pendidikan sebagian besar tamatan SMA (50\%), sarjana (2\%), tamat SD (18\%), SMP (14\%), Tidak tamat SD (16\%). Dari sisi pemilikan lahan, lahan sawah rata-rata 49 Are (efektif 30-35 Are) dan lahan kering 1,85 $\mathrm{Ha}$ (tetapi kurang produkktif). Selanjutnya dari segi tingkat pendapatan, sebagian besar berpendapatan 1,0 juta-1,5 juta/bulan (64\%), pendapatan kurang dari 1,0 juta (14\%), dan pendapatan 2 juta atau lebih (22\%).

\section{Saran}

1. Warga masyarakat di sekitar KEK Mandalika perlu mendapatkan dukungan dari pihak pemerintah, pengelola (PT.ITDC), dari para pengusaha terkait pihak lain yang terkait, untuk penguatan kapasitas/kemandirian, sehingga mereka mampu merealisasikan kesiapannya untuk berkontribusi dalam pengembangan KEK Mandalika. Dukungan dan atau di masyarakat dapat berupa informasi, pelatihan/pengolahan, kemudahaan berusaha, permodalan dan lainnya.

2. Penelitian langkah yang perlu dilakukan adaalah studi kelayakan usaha beberapa bidang usaha, seperti perdagangan dan perikanan/nelayan.

3. Perlu juga dilakukan studi pendalaman terkait minat masyarakat menekuni bidang pertanian. 


\section{DAFTAR PUSTAKA}

Anonim, 2004. UU No.32 tahun 2004 tentang Pemerintahan Daerah, Pemerintah Republik Indonesia, Jakarta

Anonim, 2016. Laporan Realisasi Pendapatan dan Belanja Daerah 2016. Pemerintah Kabupaten Lombok, Praya

Ardana, I Gusti Lanang dkk. 2018. Pengaruh Pengembangan Kawsan Ekonomi Khusus (KEK) Mandalika Resort terhadap Penerimaan Daerah dari Sektor Pariwisata di Kabupaten Lombok Tengah. LPPM Universitas Mataram: Mataram

Austriana, Ida. 2005, "Analisis Faktor yang Mempengaruhi Penerimaan Daerahdari Sektor Pariwisata". Universitas Diponegoro.

AR, Mustopadidjaya. 1997.Sistem dan Proses Penyusunan APBDN, Modul pada Program Diklat TMPP-D Angkatan XV, Makassar.

Arief Hartoko (2009); Faktor-Faktor Yang mempengaruhi Pendapatan Daerah Dari Sektor Pariwisata DiKotamadya Malang. Universitas Pembangunan Nasional "Veteran" Jawa Timur.

Badan Pusat Statistik, 2017, Lombok Tengah Dalam Angka, Kabupaten Lombok Tengah.

Eka, Arief Atmaja. 2011. Analisis Faktor-faktor yang Mempengaruhi Pendapatan Asli Daerah di Kota Semarang. www.google.com.

H.Mhd,Syafi'i. 2003. "Pengaruh Penerimaan Pajak Daerah dan Retribusi Daerah Terhadap Alokasi Anggaran Pembangunan Sektor Transportasi Di Propinsi Sumatera Utara (tesis)". Medan: Universitas Sumatera Utara.

Lomboknews.com, 2015. Pengembangan Ekonomi Khusus Mandalika Resort

Manan, Abdul dkk. 2012. Kesiapan Provinsi Nusa Tenggara Barat sebagai Pintu Gerbang Pariwisata Nasional. LPPM Universitas Mataram; Mataram

Mardiasmo. 2002. Otonomi dan Manajemen Keuangan Daerah. Penerbit Andi. Yogyakarta

Natawijaya, (2000, "Keuangan Daerah dan Kebijaksanaan Fiskal”, Gobel, Jakarta.

Sugiyono. 2010. Statistik Untuk Penelitian. Bandung: Alfabeta Bandung.

Yoeti, Oka, (2008), "Ekonomi Pariwisata (Introduksi, Informasi dan Implementasi)", PT Kompas Media Nusantara, Jakarta

PT.IDC,2017,Adendum Andal dan RKL-RPL 